\title{
OBITUARY
}

\section{IN MEMORIAM - NIKOLAI PETROVICH SAMCHENKO}

Nikolai Petrovich Samchenko died on May 12, 1994. He was a well known scientist in the fields of heterogeneous catalysis and chemical kinetics, a doctor of chemical science, professor, and laureate of the L.V.Pisarzhevskii Ukraine National Science Academy.

Nikolai Petrovich Samchenko was born in Kiev on October 18, 1933. He left the Chemical Faculty of the T. Shevchenko Kiev State University in 1957 and almost of all of his work since then was associated with the L. V. Pisarzhevski Institute of Physical Chemistry, Ukraine National Science Academy.

N. P. Samchenko's principal work was connected with the creation of scientific bases for the choice of catalysts, the elucidation of the mechanism of catalysts in such important processes as the synthesis of ammonia and of alcohols from $\mathrm{CO}$ and $\mathrm{H}_{2}$, the condensation of methanol, the hydrogenation of phenols, the hydroisomerization of $n$-alkanes. An important part of the theory of preparation and technology of catalysts developed by N. P. Samchenko pertains to their modification, the control of their chemical composition, the nature of the active centres and the structure of the substances.

In recent times N. P. Samchenko and his coworkers carried out a series of studies on catalytic syntheses based on methanol and other one-carbon molecules, established the basic physicochemical factors which determine the catalytic properties of various types of compound in these redox and acid-base reactions.

The scientific approaches developed by N. P. Samchenko permitted the creation, improvement and practical application of a whole series of catalysts in industrially important processes: the synthesis of ammonia, hydrogenation of oils, oxidation of durene to pyromellitic dianhydride, etc..

N. P. Samchenko published more than 100 scientific papers and monographs and a large number of patents.

His unusual way of thinking, his lively nature, his great humanity and scientific probity all drew young people to $\mathrm{N}$. P. Samchenko. He created a scientific school which included 3 doctorates and 8 candidates of science. However the group who could be considered N. P. Samchenko's colleagues, those who turned to him for serious thoughtful help, qualified consultation and advice, was considerably larger. N. P. Samchenko frequently contributed reports to scientific conferences at different levels.

Nikolai Petrovich Samchenko was a talented hard working researcher and an enthusiastic scientist.

Nikolai Petrovich Samchenko's memory will always remain bright in the hearts of those who knew him and worked with him.

Translated from Teoreticheskaya i Éksperimental'naya Khimiya, Vol. 30, No. 1, p. 61, January-February, 1994. 